\title{
Insights into Predictors of Vaccine Hesitancy and Promoting Factors in Childhood Immunization Programs-A Cross-Sectional Survey in Cameroon
}

\author{
Jonas Kemeugni Ngandjon ${ }^{1, *}$, Thomas Ostermann ${ }^{2}$, Virgile Kenmoue ${ }^{3}$ and Alfred Laengler 4 \\ 1 Institute of Pediatric, Faculty of Health, University of Witten/Herdecke, 58448 Witten, Germany \\ 2 Department for Psychology and Statistics, Faculty of Health, University of Witten/Herdecke, \\ 58448 Witten, Germany; thomas.ostermann@uni-wh.de \\ 3 Department for Human Medicine, Faculty of Health, Université des Montagnes, \\ Bangangté BP 208, Cameroon; jboom@gmx.de \\ 4 Department for Human Medicine, Institute of Pediatric, Faculty of Health, University of Witten/Herdecke, \\ 58448 Witten, Germany; alfred.laengler@uni-wh.de \\ * Correspondence: kjonas25@yahoo.fr; Tel.: +49-9131-605-5913
}

check for

updates

Citation: Kemeugni Ngandjon, J.;

Ostermann, T.; Kenmoue, V.;

Laengler, A. Insights into Predictors of Vaccine Hesitancy and Promoting Factors in Childhood Immunization Programs-A Cross-Sectional Survey in Cameroon. Int. J. Environ. Res. Public Health 2022, 19, 2721. https:// doi.org/10.3390/ijerph19052721

Academic Editor: Roger E. Thomas

Received: 11 December 2021

Accepted: 16 February 2022

Published: 26 February 2022

Publisher's Note: MDPI stays neutral with regard to jurisdictional claims in published maps and institutional affiliations.

Copyright: (C) 2022 by the authors. Licensee MDPI, Basel, Switzerland. This article is an open access article distributed under the terms and conditions of the Creative Commons Attribution (CC BY) license (https:// creativecommons.org/licenses/by/ $4.0 /)$.

\begin{abstract}
Background: Vaccination is claimed to be a key intervention against the COVID-19 pandemic. A major challenge today is to increase vaccine acceptance as vaccine hesitancy has delayed the eradication of polio. This study aimed to identify predictors associated with vaccine acceptance in the context of the Expanded Program on Immunization among parents of children between the ages of 12 to 23 months in the Foumbot district, Cameroon. Methods: The design of this study is a cross-sectional survey. A total of 160 mothers of children between the ages of 12 to 23 months were selected using a simple random sampling technique. A pre-tested structured questionnaire was used for data collection. Incomplete vaccination status was considered "vaccine hesitancy". Data was analyzed along with $95 \%$ confidence intervals and the $p$-value $<0.05$. The results showed $60 \%$ vaccine acceptance and $40 \%$ vaccine hesitancy. Factors such as age-appropriate vaccination, knowledge of vaccine-preventable diseases (VPD), and religion were associated with vaccine acceptance. Conclusion: Poor knowledge of VPDs is a matter of concern as it contributes to vaccine hesitancy. The study findings provide the basis to heighten health education, the public perceived threat of the VPDs, and the consequences if no measures are taken to ensure health.
\end{abstract}

Keywords: vaccine hesitancy; vaccine acceptance; childhood vaccination; knowledge of vaccinepreventable diseases; vaccination status; COVID-19; health education

\section{Background}

Early vaccination success and necessities to eradicate communicable diseases brought widespread vaccine acceptance, and immunization programs have significantly decreased the incidence of numerous diseases in many parts of the world [1,2]. As the COVID19 pandemic is threatening the world, the advent of COVID-19 vaccines was widely considered a key intervention in disease control. In addition to the Expanded Program on Immunization (EPI), which is a free immunization program to reach each child with polio, measles, tetanus, diphtheria, pertussis, and tuberculosis vaccines, governments in low-income countries have also launched the COVID-19 immunization program [2-4]. Reports from the World Health Organization (WHO) show that delays in polio eradication are linked to vaccine hesitancy among parents [2]. Therefore, the success of immunization programs depends not only on vaccines supply but also on vaccine acceptance. In 2020, many countries had still not achieved $80 \%$ polio herd immunity (three polio vaccine doses) despite the availability of vaccines: Cameroon (70\%), the Democratic Republic of Congo (59\%), Nigeria (57\%), and Central African Republic (46\%) [1]. During the COVID-19 
pandemic, as COVID-19 vaccines arrived in Africa, Nigeria administered 48\%, Cameroon $23 \%$, and the Democratic Republic of Congo administered fewer than $5 \%$ of the vaccine doses that they received [5]. By December 2021, COVID-19 vaccine hesitancy was $84 \%$ among Cameroonians, and only $2.6 \%$ of the population had received two COVID-19 vaccine doses $[1,6]$. The sole provision of vaccines does not guarantee vaccine acceptance. Due to diverse reasons and factors, vaccine hesitancy remains a concern on the African continent, although immunization programs (EPI and COVID-19 vaccines) are free of charge. Vaccine hesitancy refers to a delay in acceptance or refusal of an available vaccine. Many vaccine-hesitant parents believe that vaccines contain suspicious products, which could endanger child health [4]. The feeling that sows doubt and mistrust, as well as the spread of misinformation, both lead to a community of vaccine hesitancy. Studies of recent outbreaks of vaccine-preventable diseases (VPDs) have reported that vaccine hesitancy among parents is linked to the outbreak of VPDs throughout African countries and internationally [7-9]. In 2013, outbreaks of polio were reported in Central Africa, particularly in Cameroon, where it was reported in nine districts, including the Foumbot district [10]. Despite the EPI in this district, children with polio had not received any vaccine by the age of two. A major challenge today is to increase vaccine acceptance.

Although evidence on encouraging vaccination, in general, is useful in the context of outbreaks, vaccine acceptance poses an enormous challenge. Understanding the process of vaccine acceptance can serve as an early warning system to take action to avoid declining vaccine confidence and acceptance. This study offers a baseline of confidence levels to assess vaccine acceptance among parents and help identify where further confidencebuilding is required to increase adoption of childhood vaccination and new vaccines such as COVID-19 vaccines.

However, data on vaccine acceptance from African countries, mainly from Central Africa, is substantially limited. This indicates a need for specific research in these regions to explore the factors that contribute to parental vaccine hesitancy. Evidence from western countries will not be applicable here due to the significant differences in social and cultural contexts. Therefore, this study aimed to identify, during the EPI, the factors influencing complete childhood vaccination by sociodemographics and knowledge on vaccination among parents in the Foumbot district in Cameroon to understand the gap in formulating a comprehensive immunization program.

\section{Methods}

\subsection{Study Area}

The Foumbot district is a rural area of about $1000 \mathrm{~km}^{2}$. It is located in the Noun Division, West Region of Cameroon. The population estimate is 62,776 inhabitants (from the 2013 Census), the majority being Bamum. The predominant religion is Islam. Farming is the main occupation. The district hosts the most important fresh food market in Cameroon. The EPI is provided free of charge at health facilities. In 2013, a polio outbreak was reported in the district [10].

\subsection{Study Design}

A cross-sectional survey of parents of children aged 12 to 23 months was conducted from 1st July to 31st October 2014. The EPI coverage and the factors associated with childhood vaccination were assessed. Only the parents of the children were interviewed. Survey participants were selected randomly according to coverage cluster survey sampling [11-14]. Vaccination coverage was evaluated by means of the vaccination booklet and the EPI registers.

\subsection{Sample Size Determination}

Using the sample size calculation methodology presented in the WHO Immunization Coverage Cluster Survey Reference Manual (WHO/IVB/04.23), the sample size required was determined using the coverage of $64 \%$ obtained in the western region, a precision of 
$\pm 10 \%$, a type 1 error of $10 \%$, and a design effect of 1.5 , in conformity with the standard WHO methodology $[12,13]$. Thus, the calculated minimum number of children required was 147.

\subsection{Participants}

During the investigation, data from 160 children and 160 parents were randomly collected in the district. The sampling process was performed according to the simple random sample method [11,12]. The first household was randomly chosen from each selected cluster. Each household was chosen randomly, such that each household had the same probability in the cluster of being chosen during the sampling process [15].

\subsection{Data Collection}

The data was collected using a structured questionnaire. The questionnaire covers sociodemographic factors and parents' knowledge of VPDs. Prior to data collection, the questionnaire was pretested on a $5 \%$ sample of a similar population. The vaccination status of the child was established by the records in the vaccination booklet, the records in the EPI registers, or by the presence of scar in the case of the BCG vaccine.

\subsection{Independent Variables}

The independent variables included sociodemographic characteristics and the parent's knowledge regarding vaccination and VPDs. The sociodemographic variables included age group $(<25,25-34,>34)$, education (no formal education, primary, secondary, university), occupation (formal sector, informal sector), marital status (married, single, divorced, and widowed), religion (Catholic, Protestant, Muslim, and Animist). To collect data on knowledge about vaccination and VPDs, parents were asked if they knew the reason for vaccinating (prevent the occurrence of diseases, decrease the severity of diseases, no idea), had knowledge of VPDs (good knowledge, poor knowledge), knew age-appropriate vaccination (at birth, no idea, other date), were aware of the vaccination schedule (be aware), and if they retained the vaccination booklet (keep). The response was recorded as 'Yes/No'.

\subsection{Outcome Variable}

A close-ended question inquiring whether the parent has completed the EPI was used as the outcome variable. The outcome variable for this study was complete vaccination. Complete vaccination was defined as a child who received one dose of BCG and measles and three doses of OPV before the age of two. Children missing one dose of these vaccines were defined as incomplete vaccination. Complete vaccination was considered 'vaccine acceptance', whereas incomplete vaccination and no vaccination were considered 'vaccine hesitancy'.

\subsection{Data Processing and Analysis}

The data from the interview was coded and entered into a computer database using Microsoft Office Excel 2010. Descriptive statistics were performed by means of the statistical software program SPSS. The Fisher test was used, and the odds ratios (OR) were calculated along with 95\% confidence intervals (CI). A bivariate analysis was conducted to examine the association of vaccination status with each independent variable. Based on this, only independent variables that had significant bivariate associations with vaccination status were considered for the multivariate logistic regression. The stepwise multivariate analysis was used. Models were generated according to the type "forward selection". Akaike's information criterion (AIC) and Schwarz's Bayesian information criteria (BIC) were used to inform the selection of models and to assess the goodness of fit. The AIC and BIC values were compared in successive models, and the model with the lowest value was considered the best-fit model [16]. In addition, the likelihood ratio test and the area under receiver operating characteristics (AUC) curve were used to assess the predictive quality of the model. 


\subsection{Ethical Clearance}

This study obtained authorization to be carried out from the Faculty of Medicine of the Universite des Montagnes and the health authorities of the Foumbot district. Verbal informed consent was required for each participant prior to the administration of the questionnaire.

\section{Results}

\subsection{Prevalence of Vaccine Acceptance}

Table 1 present the vaccination coverage in the study area. It appears that $96(60 \%)$ of the 160 respondents completed the EPI. About $62(38.75 \%)$ of the respondents had not completed the EPI, and 2 (1.25\%) of the respondents had not started with the EPI. Therefore, $64(40 \%)$ of respondents indicated vaccine hesitancy. The dropout rate between the initial vaccine of BCG and the final vaccine of measles was $36 \%$.

Table 1. The EPI vaccines coverage of children 12-23 months from this study compared to data for Cameroon from the Sociodemographic Health Survey (DHS) in 2018.

\begin{tabular}{cccc}
\hline Vaccines & $\begin{array}{c}\text { Case } \\
\text { Present Study } \\
(\boldsymbol{n}=\mathbf{1 6 0}) \\
\text { Case }\end{array}$ & $\begin{array}{c}\text { Percentage } \\
\text { Present Study } \\
(\boldsymbol{n}=\mathbf{1 6 0}) \\
\mathbf{\%}\end{array}$ & $\begin{array}{c}\text { Percentage } \\
\text { Cameroon } \\
\text { DHS (2018) } \\
\mathbf{\%}\end{array}$ \\
\hline BCG & 158 & 98.8 & 87.1 \\
\hline DPT 1 & 144 & 90 & 83 \\
\hline DPT 2 & 134 & 83.8 & 79 \\
\hline DPT 3 & 125 & 78.1 & 72 \\
\hline OPV 1 & 143 & 89.4 & 86 \\
\hline OPV 2 & 134 & 83.8 & 60 \\
\hline OPV 3 & 124 & 77.5 & 69.3 \\
\hline VAA (Yellow Fever & 101 & 63.1 & 65 \\
\hline VAR (Measles) & 101 & 63.1 & 52 \\
\hline Not vaccinated & 2 & 1.25 & \\
\hline Completely & 96 & 60 & \\
vaccinated & & & 50 \\
\hline
\end{tabular}

\subsection{Barriers in Vaccine Acceptance}

Table 2 present the reasons for missing vaccination among parents whose children had incomplete vaccination status. Eleven (17.2\%) of the sixty-four vaccine hesitant parents declared a lack of information regarding childhood vaccination. Additionally, 11 (17.2\%) reported a lack of confidence in the EPI, whereas $42(65.6 \%)$ reported poor quality of vaccination services.

\subsection{Sociodemographic in Vaccine Acceptance}

Table 3 show the results of the bivariate analysis. The factors marital status, religion, knowledge of VPDs, age-appropriate vaccination, and being aware of the vaccination schedule were significantly associated with complete vaccination at $p<0.05$. The odds of receiving a complete vaccination among children whose parents were single were 3.23 $(\mathrm{OR}=3.23 ; 95 \% \mathrm{CI}: 1.03,10.09)$ times higher than children whose parents were married. Muslim parents had $0.27(\mathrm{OR}=0.27 ; 95 \% \mathrm{CI}$ : $0.12,0.61)$ times lower odds of completely vaccinating their children than parents from other religions. Children whose parents started vaccination at birth were $2.5(\mathrm{OR}=2.5 ; 95 \% \mathrm{CI}: 1.12,5.55)$ times more likely of being completely vaccinated compared to children whose parents started later. Parents who were aware of the vaccination schedule were $3.52(\mathrm{OR}=3.52 ; 95 \% \mathrm{CI}: 1.43,8.65)$ times more 
likely to have completely vaccinated their child compared to parents who were not aware of it. The odds of being completely vaccinated among children whose parents had good knowledge of VDPs were 3.08 (OR = 3.08; 95\% CI: 1.21, 7.85) times higher than children whose parents had poor knowledge of VPDs.

Table 2. Given reasons by parents for missing the EPI $(n=64)$.

\begin{tabular}{|c|c|c|c|}
\hline \multicolumn{2}{|c|}{ Barriers in Vaccine Acceptance: } & Cases & Percentage \\
\hline \multirow{3}{*}{ Missing Information } & Ignores the necessity for vaccination & 6 & \multirow{3}{*}{$17.2 \%$} \\
\hline & Ignores the necessity of the 2nd and 3rd dose & 3 & \\
\hline & Fear of adverse effects & 2 & \\
\hline \multirow{2}{*}{ No interest } & Discouraged by the entourage & 3 & \multirow{2}{*}{$17.2 \%$} \\
\hline & Does not trust vaccination & 8 & \\
\hline \multirow{4}{*}{ Quality of vaccination services } & Absence of the vaccination personnel & 1 & \multirow{4}{*}{$65.6 \%$} \\
\hline & Vaccines not available & 4 & \\
\hline & Long waiting time & 3 & \\
\hline & No flexible time schedule & 34 & \\
\hline
\end{tabular}

Table 3. Sociodemographic characteristics of participants $(n=160)$ and their associations with complete childhood immunization.

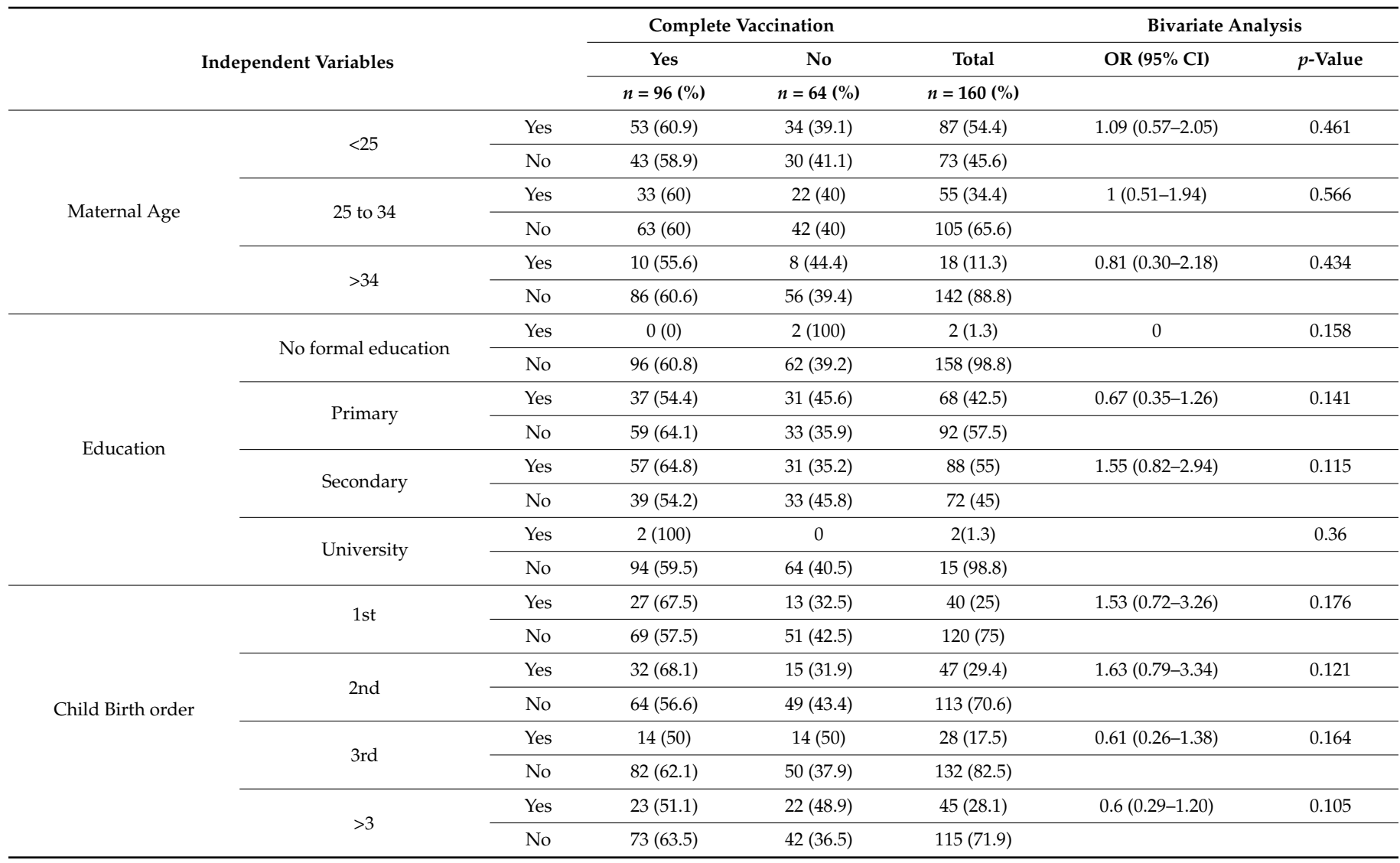


Table 3. Cont.

\begin{tabular}{|c|c|c|c|c|c|c|c|}
\hline \multirow{2}{*}{\multicolumn{3}{|c|}{ Independent Variables }} & \multicolumn{2}{|c|}{ Complete Vaccination } & \multirow{3}{*}{$\begin{array}{c}\text { Total } \\
n=160(\%)\end{array}$} & \multicolumn{2}{|c|}{ Bivariate Analysis } \\
\hline & & & \multirow{2}{*}{$\begin{array}{c}\text { Yes } \\
n=96(\%) \\
\end{array}$} & \multirow{2}{*}{\begin{tabular}{c|c|} 
No \\
$n=64(\%)$ \\
\end{tabular}} & & \multirow[t]{2}{*}{ OR $(95 \% \mathrm{CI})$} & \multirow[t]{2}{*}{$p$-Value } \\
\hline \multirow{8}{*}{ Marital Status } & \multirow{3}{*}{ Single } & & & & & & \\
\hline & & Yes & $17(81)$ & $4(19)$ & $21(13.1)$ & $3.23(1.03-10.09)$ & 0.028 \\
\hline & & No & $79(56.8)$ & $60(43.2)$ & $139(86.9)$ & & \\
\hline & \multirow{2}{*}{ Married } & Yes & $79(57.2)$ & $59(42.8)$ & $138(86.3)$ & $0.393(0.13-1.12)$ & 0.06 \\
\hline & & No & 17 (77.3) & $5(22.7)$ & $22(13.8)$ & & \\
\hline & \multirow{2}{*}{ Widow } & Yes & 0 & $1(100)$ & $1(0.6)$ & 0 & 0.4 \\
\hline & & No & $96(60.4)$ & $63(39.6)$ & $159(99.4)$ & & \\
\hline & Divorced & No & $96(60)$ & $64(40)$ & $160(100)$ & & \\
\hline \multirow{7}{*}{ Religion } & \multirow{2}{*}{ Catholic } & Yes & $12(75)$ & $4(25)$ & $16(10)$ & $2.14(0.65-6.96)$ & 0.1533 \\
\hline & & No & $84(58.3)$ & $60(41.7)$ & $144(90)$ & & \\
\hline & \multirow{2}{*}{ Protestant } & Yes & $24(82.8)$ & $5(17.2)$ & $29(18.1)$ & $3.93(1.41-10.94)$ & 0.004 \\
\hline & & No & $72(55)$ & $59(45)$ & $131(81.9)$ & & \\
\hline & \multirow{2}{*}{ Muslim } & Yes & $60(52.2)$ & $55(47.8)$ & 115 (71.9) & $0.27(0.12-0.61)$ & 0.001 \\
\hline & & No & $36(80)$ & $9(20)$ & $45(28.1)$ & & \\
\hline & Animist & No & $96(60)$ & $64(40)$ & $160(100)$ & & \\
\hline \multirow{4}{*}{ Occupations } & \multirow{2}{*}{ Formal sector } & Yes & $8(66.7)$ & $4(33.3)$ & $12(7.5)$ & $1.36(0.39-4.73)$ & 0.434 \\
\hline & & No & $88(59.5)$ & $60(40.5)$ & $148(92.5)$ & & \\
\hline & \multirow{2}{*}{ Informal Sector } & Yes & $88(59.5)$ & $60(40.5)$ & $148(92.5)$ & $0.73(0.21-2.54)$ & 0.434 \\
\hline & & No & $8(66.7)$ & $4(33.3)$ & $12(7.5)$ & & \\
\hline \multirow{6}{*}{ Reason for vaccinating } & \multirow{2}{*}{$\begin{array}{l}\text { Prevent the occurrence } \\
\text { of diseases }\end{array}$} & Yes & $64(58.7)$ & $45(41.3)$ & $109(68.1)$ & $0.84(0.42-1.67)$ & 0.379 \\
\hline & & No & $32(62.7)$ & $19(37.3)$ & $51(31.9)$ & & \\
\hline & \multirow{2}{*}{$\begin{array}{l}\text { Decrease the severity } \\
\text { of diseases }\end{array}$} & Yes & $1(50)$ & $1(50)$ & $2(1.2)$ & $0.66(0.04-10.79)$ & 0.641 \\
\hline & & No & $95(60.1)$ & $63(39.9)$ & $158(98.8)$ & & \\
\hline & \multirow{2}{*}{ No idea } & Yes & $31(63.3)$ & $18(36.7)$ & 49 (30.6) & $1.2(0.61-2.4)$ & 0.35 \\
\hline & & No & 65 (58.6) & $46(41.4)$ & $111(69.4)$ & & \\
\hline \multirow{4}{*}{$\begin{array}{l}\text { Knowledge of VPD and } \\
\text { communicable diseases }\end{array}$} & \multirow{2}{*}{ Good knowledge } & Yes & $88(63.7)$ & $50(36.2)$ & $138(86.2)$ & $3.08(1.21-7.85)$ & 0.01 \\
\hline & & No & $8(36.3)$ & $14(63.6)$ & $22(13.8)$ & & \\
\hline & Poor knowledge & Yes & $8(36.4)$ & $14(63.6)$ & $22(13.8)$ & $0.32(0.12-0.82)$ & 0.014 \\
\hline & 1001 Niturienge & No & $88(63.8)$ & $50(36.2)$ & $138(86.3)$ & & \\
\hline & At Rirth & Yes & $83(64.3)$ & $46(35.7)$ & $129(80.6)$ & $2.5(1.12-5.55)$ & 0.02 \\
\hline & At Dirtn & No & $13(41.9)$ & $18(58.1)$ & $31(19.4)$ & & \\
\hline Age-appropriate & Noidea & Yes & $11(44)$ & $14(56)$ & $25(15.6)$ & $0.4(0.19+1.09)$ & 0.06 \\
\hline vaccination & Noviuea & No & $85(63)$ & $50(37)$ & $135(84.3)$ & & \\
\hline & Other date & Yes & $2(33.3)$ & $4(66.6)$ & $6(3.7)$ & $0.32(0.06-1.79)$ & 0.17 \\
\hline & Giner uate & No & $94(60)$ & $60(40)$ & $154(96.9)$ & & \\
\hline Be aware of the & Be aware & Yes & $29(80.6)$ & $7(19.4)$ & $36(22.5)$ & $3.52(1.43-8.65)$ & 0.002 \\
\hline vaccination schedule & De aware & No & $67(54)$ & $57(46)$ & $124(77.5)$ & & \\
\hline Retention of the & Keep & Yes & $88(62)$ & $54(38)$ & $142(88.8)$ & $2.04(0.76-5.48)$ & 0.121 \\
\hline vaccination booklet & $x^{2}$ & No & $8(44.4)$ & $10(55.6)$ & $18(11.3)$ & & \\
\hline
\end{tabular}

\subsection{Multivariate Logistic Regressions}

Table 4 present the results of the stepwise method based on forward selection to purposely assess the contribution of each independent variable towards the prediction of complete childhood vaccination. The effect of the variables (religion, age-appropriate vaccination, knowledge of VPDs) was statistically significant (that is with Sig. $<0.05$ ). This means that the variables found in Table 4 contribute significantly to the explanatory power of parents' decision to complete vaccination. However, the following variables (marital status and being aware of the vaccination schedule) were dropped from the final model with the stepwise method of forward selection since they did not contribute towards the prediction of complete vaccination in Supplementary Materials. 
Table 4. Information criteria of multivariate logistic regression analysis of vaccination decisionmaking in parents with children between 12 to 23 months $(n=160)$.

\begin{tabular}{|c|c|c|c|c|c|c|c|c|}
\hline \multirow{2}{*}{ Model } & \multirow{2}{*}{ Action } & \multirow{2}{*}{ Effect(s) } & \multicolumn{3}{|c|}{ Model Fitting Criteria } & \multicolumn{3}{|c|}{ Effect Selection Tests } \\
\hline & & & AIC & BIC & -2 Log-Likelihood & Chi-square $^{a}$ & df. & Sig. \\
\hline Step 0 & Entered & Constant & 85.70 & 88.78 & 83.70 & . & & \\
\hline Step 1 & Entered & Religion & 76.58 & 82.73 & 72.58 & 11.12 & 1 & 0.001 \\
\hline Step 2 & Entered & $\begin{array}{c}\text { Age-appropriate } \\
\text { vaccination }\end{array}$ & 67.74 & 76.97 & 61.74 & 10.84 & 1 & 0.001 \\
\hline Step 3 & Entered & Knowledge of VPDs & 64.16 & 76.46 & 56.14 & 5.58 & 1 & 0.018 \\
\hline
\end{tabular}

Stepwise Method: Forward Selection. The Chi-Square for entry is based on the likelihood ratio test.

Table 5 depict the model fitting information for the inclusion of the three variables that were found significant in Table 4. The final model with the least log-likelihood (56.16), AIC (64.16), BIC (76.46), and a degree of freedom of 3 was highly significant at the $5 \%$ level of significance. This means the final model based on the likelihood ratio test confirms that the multivariate logistic regression comprising of the three predictors fits the data better and is more effective than by chance towards the prediction of childhood vaccination status. The predictive utility of the final model was fair, with an AUC of 0.73 .

Table 5. Model fitting information of multivariate logistic regression analysis of vaccination decisionmaking in parents with children between 12 to 23 months $(n=160)$.

\begin{tabular}{|c|c|c|c|c|c|c|c|}
\hline \multirow{2}{*}{ Model } & \multicolumn{3}{|c|}{ Model Fitting Criteria } & \multicolumn{3}{|c|}{ Likelihood-Ratio-Tests } & \multirow[t]{2}{*}{ AUC } \\
\hline & AIC & BIC & -2 Log-Likelihood & Chi-Square & df. & Sig. & \\
\hline Only Intercept & 85.70 & 88.78 & 83.70 & & & & \\
\hline Final & 64.16 & 76.46 & 56.16 & 27.54 & 3 & 0.0001 & 0.73 \\
\hline
\end{tabular}

\section{Discussion}

This study examined the association and influence of sociodemographic factors and knowledge of VPDs on complete childhood vaccination. The complete childhood vaccine acceptance was $60 \%$ [Table 1]. This was high as compared to the three Cameroonian regions West (54\%), Adamawa (38\%), and North (36\%) [17]. In total, 65.6\% of the vaccinehesitant parents mentioned barriers linked to the quality of vaccination services [Table 2]. Similar results were reported in studies carried out in Bangladesh, India, the Philippines, Ethiopia, and Malawi [18,19]. In these countries, shortcomings were identified at the interface between the vaccination provider and the parents. Thus, the pools of unvaccinated children increased. In 2015, Cameroon was still classified as having an acute shortage of health personnel [20]. Researchers in Vietnam observed that the advice of a healthcare professional was the major factor that changed the view of parents who had previously refused vaccination or had delayed vaccination [21,22]. Therefore, contact with a healthcare professional is an important factor in vaccine acceptance. The results of this study showed that age-appropriate vaccination was significantly associated with complete childhood vaccination. Once starting the vaccination program at birth, the likelihood to complete the EPI increased by 2.5 [OR = 2.5] [Table 3]. A study performed in 2000 in a rural community of the Edo State in Nigeria showed that early vaccination of children increases the awareness of the parents towards VPDs and vaccination [23]. Administering the first vaccine at birth is an important step for building confidence in medical interventions and raising parental awareness about VPDs and the role that the vaccination can play in promoting child health. However, we found that $36 \%$ of the children had not completed the vaccination program, although $98 \%$ had received the BCG vaccine at birth [Table 1] This study revealed that $17.2 \%$ of the vaccine-hesitant parents had concerns about the 
quality of information on the vaccination. Additionally, 17.2\% did not have trust in the vaccine [Table 2]. This indicates that the awareness towards VPDs was not reached, and the confidence in medical interventions was not established. This study also revealed that religion was significantly associated with complete childhood vaccination [Table 3]. Data from India, Kenya, and Nigeria showed that vaccination in countries with traditional societies was more often associated with religious leaders as they are key stakeholders in disease prevention [4,24-30]. In these countries, vaccine hesitancy was driven by religious leaders as they called for a boycott of polio vaccination campaigns citing safety concerns with vaccines so that medical interventions intersected with cultural perception [31-35]. Due to past experiences relating to the slave trade and the colonization of Africa, vaccination has become suspicious as it is often linked to the conspiracy theory that western countries want to depopulate the African continent. Furthermore, many people believe in vaccineinduced female infertility $[4,24,26,27,34-37]$. These previous studies showed that vaccine acceptance was not generated by religious principles but by how health information was conveyed, perceived, and understood. The results of this study showed that knowledge of VPDs was a significant predictor to complete the EPI. Parents with good knowledge of VPDs [OR = 3.08] had a higher likelihood of completing the EPI. This finding is similar to an international study carried out in five African countries (Democratic Republic of Congo, Benin, Uganda, Malawi, and Mali), which reported that during the COVID-19 pandemic, individuals who perceived taking the COVID-19 vaccine as important to protect themselves had the highest vaccine acceptance odd [36]. In these countries, vaccine acceptance was positively associated with COVID-19 knowledge and threat regarding COVID-19. However, as information that COVID-19 vaccine-induced death spread within communities [38], a study indicated a low-risk perception of COVID-19 among Sub-Sahara Africans [39]. Therefore, fear of adverse effects from vaccines "makes sense". Having a perceived low risk of disease can make vaccination less of a requirement. According to the Health Believe Model (HBM), the understanding of diseases enables people to perceive threat and thus, vaccine acceptance increases [28,40-42]. With reference to studies carried out in Kenya, Nigeria, Senegal, Turkey, and Thailand [34,43-47], health education was best suited to fill existing knowledge gaps and motivate parents to get their children vaccinated; this was the primary influence on the participants' decision on vaccination. Thereby, knowledge of VPDs raises parents' awareness of the healthcare, prevention, and the consequences of diseases for the child if measures are not taken to ensure health. This finding showed that vaccine acceptance increases as parents' knowledge of VPDs increases. Therefore, the implementation of health education programs may be most beneficial. At the same time, the local system of customs and values (background, tradition, healing concept, etc.) should be considered for people's understanding and perception of VPDs [Figure 1]. 


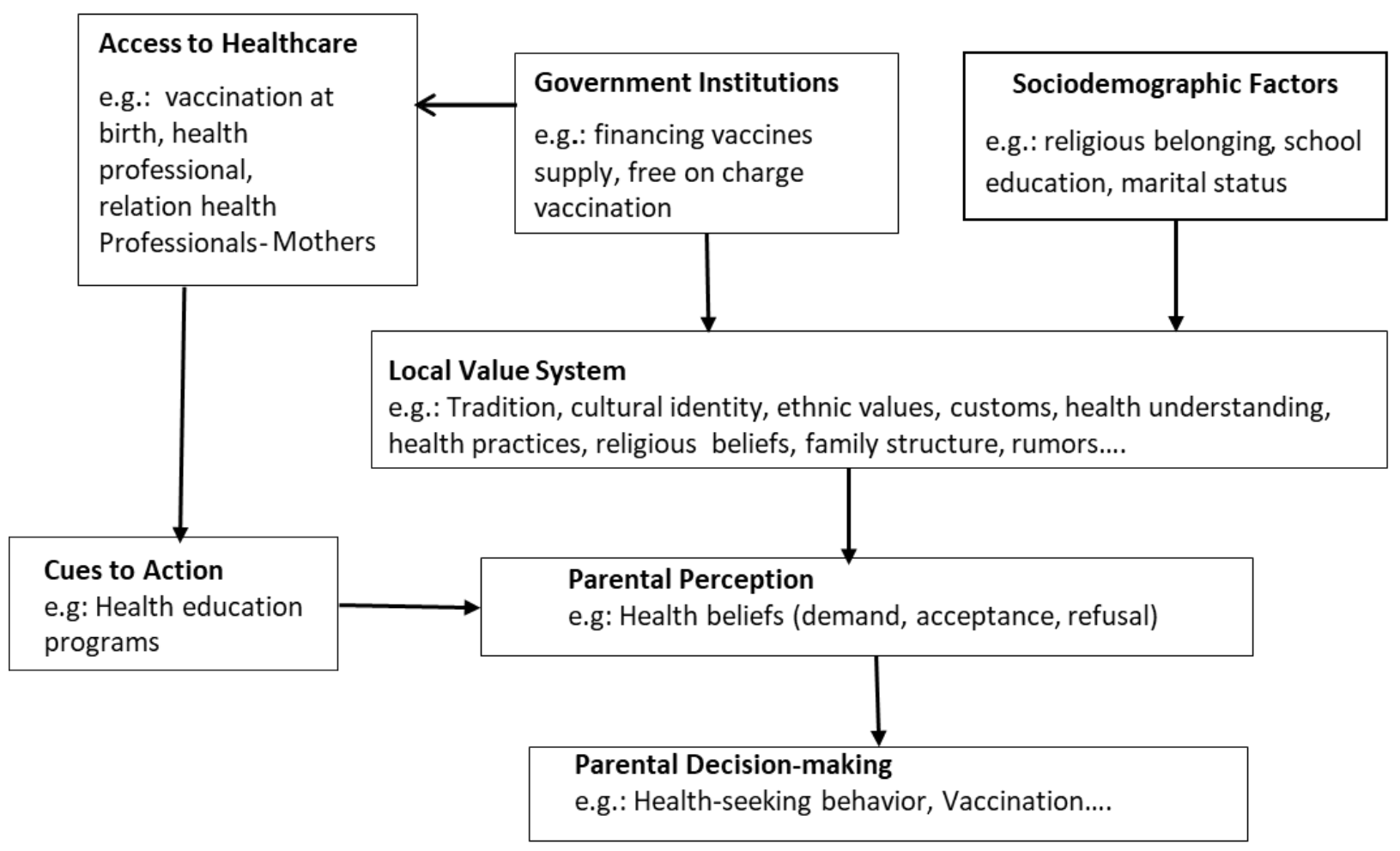

Figure 1. Proposed community-based conceptual framework of parental decision-making.

\section{Limitations of the Study}

In this study, some limitations were expected because this is a cross-sectional study, and the sampling method is susceptible to selection bias. Although the sample size was small, it is representative of the population which it resamples as it was calculated using the simple random sampling (SRS) method. Unfortunately, this method lacks the use of available knowledge concerning the population. Only the participants that were present in the district at the time of the interview and that met the survey inclusion criteria were considered in the sample.

\section{Conclusions}

This study identified knowledge of vaccine-preventable diseases as a factor influencing vaccine acceptance among parents in the Foumbot district. The low perceived threat of diseases is a matter of concern as it contributes to vaccine hesitancy. Consequently, vaccine acceptance may or may not only be based directly on a knowledgeable comprehension of the vaccination but also on the understanding of vaccine-preventable disease and the interpretation of the received information in communities [Figure 1]. The findings of this study suggest investing in health education programs to raise parents' perceived threat towards disease infections and thereby improve preventive health behaviors such as vaccination to avoid diseases. Health education programs should not exclusively be limited to avoiding diseases or how to cope with diseases. It should also consider the local understanding of health issues and diseases. Future research should investigate possibilities in understanding the dynamics of communities regarding health issues while tailoring immunization programs to the local context.

Supplementary Materials: The following supporting information can be downloaded at: https: / / www.mdpi.com/article/10.3390/ijerph19052721/s1, Table S1: Classification Table a,b_ModelIntercept.; Table S2: Variables in the Equation-Model-Intercept.; Table S3: Variables not in the EquationModel-Intercept.; Table S4: Omnibus Test of Model Coefficients-Overall Chi-square test.; Table S5: Model Summary-Full Model.; Table S6: Variables in the Equation; Table S7: Classification Table a_Stepwise Regression; Table S8: Variable in the Equation-Stepwise Regression.; Table S9: Model 
Summary—Stepwise Regression.; Table S10: Step Summary-Information Criteria; Table S11: Information for Model Fitting Criteria; Figure S1: Receiver Operating Characteristic (ROC) curve-Final Model (step 3).; Table S12: Area Under the Curve—Test Result Variable(s)—Predicted probability.

Author Contributions: Conceptualization, J.K.N. and A.L.; Formal analysis, J.K.N. and T.O.; Investigation, V.K.; Methodology, J.K.N. and A.L.; Project administration, A.L.; Supervision, A.L. and T.O.; Validation, J.K.N., A.L. and T.O.; Writing-original draft, J.K.N. All authors have read and agreed to the published version of the manuscript.

Funding: This research received no external funding.

Institutional Review Board Statement: The ethical approval Autorisation N ${ }^{\circ}$ 2014/036/UdM/PR/ CAB/CIE was obtained on the 30 June 2014 from the Institutional Ethic Committee of the Université des Montagnes. Before data collection, written consent was obtained from the respondents. No participant was below the age of 16 at the time of the study.

Informed Consent Statement: Informed consent was obtained from all subjects involved in the study.

Data Availability Statement: The datasets used and/or analyzed during the current study are available from the corresponding author on reasonable request.

Conflicts of Interest: The authors declare no conflict of interest.

\section{Abbreviations}

$\begin{array}{ll}\text { AIC } & \text { Akaike's Information Criterion } \\ \text { BCG } & \text { Bacillus Calmatte Guiren } \\ \text { BIC } & \text { Bayesian Information Criterion } \\ \text { CI } & \text { Confidence Interval } \\ \text { df } & \text { Degree of freedom } \\ \text { DPT } & \text { Diphtheria, Pertussis, Tetanus } \\ \text { EPI } & \text { Expanded Program on Immunization } \\ \text { EXP } & \text { Exponential } \\ \text { HBM } & \text { Health Belief Model } \\ \text { MCV } & \text { Measles-Containing Vaccine } \\ \text { OPV } & \text { Oral Polio Vaccine } \\ \text { OR } & \text { Odds Ratio } \\ \text { PCV } & \text { Pneumococcal Conjugate Vaccine } \\ \text { Polio } & \text { Poliomyelitis } \\ \text { REF } & \text { Reference } \\ \text { S.E. } & \text { Standard Error } \\ \text { Sig. } & \text { Significance level } \\ \text { SRS } & \text { Simple random sample } \\ \text { USA } & \text { United States of America } \\ \text { VAA } & \text { Vaccin Anti Amaril (yellow fever vaccine) } \\ \text { VAR } & \text { Vaccin Anti Rougeoleux (measles vaccine) } \\ \text { VPD } & \text { Vaccine-preventable disease } \\ \text { WHO } & \text { World Health Organization }\end{array}$

\section{References}

1. World Health Organization (WHO). Global Health Observatory Data Repository. Available online: https://apps.who.int/gho/ data/node.home (accessed on 28 December 2021).

2. World Health Organization. Immunization Agenda 2030: A Global Strategy to Leave No One Behind. Available online: https:/ / www.who.int/teams/immunization-vaccines-and-biologicals/strategies/ia2030 (accessed on 18 December 2021).

3. Cameroon Ministry of Public Health. Cameroun-Comprehensive multi-year plan for 2011-2015. 2011. Available online: https:/ / extranet.who.int/countryplanningcycles/sites/default/files/planning_cycle_repository/central_african_republic/ cmyp_car_2011-2015_en.pdf (accessed on 18 May 2011).

4. Njeru, I.; Ajack, Y.; Muitherero, C.; Onyango, D.; Musyoka, J.; Onuekusi, I.; Kioko, J.; Muraguri, N.; Davis, R. Did the call for boycott by the catholic bishops affect the polio vaccination coverage in Kenya in 2015? A cross-sectional study. Pan Afr. Med. J. 2016, 24, 120. [CrossRef] [PubMed] 
5. Adepoju, P. As COVID-19 Vaccines Arrive in Africa, Omicron is Reducing Supply and Increasing Demand. Available online: https:/ / www.nature.com/articles/d41591-021-00073-x (accessed on 13 December 2021).

6. Dinga, J.N.; Kouemou, L. Assessment of vaccine hesitanc to a COVID-19 vaccine in Cameroonian adults and its global implication Vaccines 2021, 9, 175. [CrossRef] [PubMed]

7. Abdulraheem, I.; Onajole, A.; Jimoh, A.; Oladipo, A. Reasons for incomplete vaccination and factors for missed opportunities among rural Nigerian children. J. Public Health Epidemiol. 2011, 3, 194-203.

8. Gore, P.; Madhavan, S.; Curry, D.; McClung, G.; Castiglia, M.; Rosenbluth, S.A.; Smego, R.A. Predictors of childhood immunization completion in a rural population. Soc. Sci. Med. 1999, 48, 1011-1027. [CrossRef]

9. Tanne, J.H. Measles: Two US outbreaks are blamed on low vaccination rates. BMJ 2019, 364, 1312. [CrossRef] [PubMed]

10. Ngandjon, J.K.; Laengler, A.; Ostermann, T. Community-based Programs for Childhood Immunization and Prevention of Childhood Diseases: Sustainable Support in Mothers' Decision-Making-A Health Belief Model Approach. Available online: https: / / assets.researchsquare.com/files/rs-89501/v1/3ef95e7d-c286-4d5f-9f0a-b4f4c82ee450.pdf?c=1631857859 (accessed on 13 October 2020).

11. World Health Organization. Vaccination Coverage Cluster Survey Reference Manual_WHO/IVB/04.23; World Health Organization: Geneve, Switzerland, 2005.

12. World Health Organization. The EPI Coverage Survey-WHO/IVB/08.07. Available online: https://www.who.int/ immunization/documents/MLM_module7.pdf (accessed on 12 December 2021).

13. SCHWARTZ, D. Méthodes Statistiques à L'usage des Médecins et Biologists. 1969. Available online: https://bdsp-ehesp.inist.fr/ $\mathrm{vibad} /$ index.php?action=getRecordDetail\&idt=85872 (accessed on 12 May 2021).

14. Bennett, S.; Woods, T.; Liyanage, W.; Smith, D. A simplified general method for cluster sample surveys of health in developing countries. World Health Stat. Q. 1991, 44, 98-106.

15. United Nations. Designing Household Survey Samples: Practical Guidelines; United Nations: New York, NY, USA, 2005.

16. Giancristofaro, R.A.; Salmaso, L. Model Performance Analysis and Model Validation in logistic Regression. Statistica 2003, 63, 375-396.

17. Cameroon DHS, 2018-Cameroon 2018 Demographic and Health Survey-Summary Report. Available online: https:// dhsprogram.com/publications/publication-sr266-summary-reports-key-findings.cfm (accessed on 18 December 2018).

18. Etana, B. Factors Affecting Immunization Status of Children Aged 12-23 Months in Ambo Woreda, West Shewa Zone of Oromia Regional State. Available online: http:/ /213.55.95.56/handle/123456789/6843 (accessed on 15 May 2011).

19. Streefland, P.H.; Chowdhury, A.M.; Ramos-Jimenez, P. Quality of vaccination services and social demand for vaccination in Africa and Asia. Bull. World Health Organ. 1999, 77, 722. [PubMed]

20. Tandi, T.E.; Cho, Y.; Akam AJ, C.; Afoh, C.O.; Ryu, S.H.; Choi, M.S.; Kim, K.; Choi, J.W. Cameroon public health sector: Shortage and inequalities in geographic distribution of health personnel. Int. J. Equity Health 2015, 14, 1-12. [CrossRef]

21. Gust, D.A.; Darling, N.; Kennedy, A.; Schwartz, B. Parents with doubts about vaccines: Which vaccines and reasons why. Pediatrics 2008, 122, 718-725. [CrossRef]

22. Dinh, T.A.; Rosenthal, S.L.; Doan, E.D.; Trang, T.; Pham, V.H.; Tran, B.D.; Tran, V.D.; Phan, G.A.B.; Chu, H.K.H.; Breitkopf, C.R Attitudes of mothers in Da Nang, Vietnam toward a human papillomavirus vaccine. J. Adolesc. Health 2007, 40, 559-563. [CrossRef] [PubMed]

23. Odusanya, O.O. Age-Appropriate Immunization Coverage in a Rural community in Edo State, Nigeria. J. Niger. Infect. Control Assoc. 2000, 3, 9. [CrossRef]

24. Kapp, C. Surge in polio spreads alarm in northern Nigeria. Rumours about vaccine safety in Muslim-run states threaten WHO's eradication program. Lancet 2003, 362, 1631. [CrossRef]

25. IRIN. NIGERIA: Muslim Suspicion of Polio Vaccine Lingers on. 2013. Available online: https://www.thenewhumanitarian.org/ report / 48667/nigeria-muslim-suspicion-polio-vaccine-lingers\#: \{\}:text=The $\% 20$ success $\% 20$ of $\% 20$ the $\% 20$ global, used $\% 20 f o r \%$ 20immunisation\%20in\%20Nigeria (accessed on 19 February 2004).

26. Muslim Clerics Finally Embrace Polio Campaign; Retrieved; Associated Press: New York, NY, USA, 2015; Available online: https:/ / www.nbcnews.com/health/health-news/muslim-clerics-finally-embrace-polio-campaign-flna1c9450705 (accessed on 22 March 2002).

27. Warraich, H.J. Religious Opposition to Polio Vaccination. Emerg. Infect. Dis. 2009, 15, 978. [CrossRef]

28. Nichter, M. Special issue on the Debate on Selective or Comprehensive Primary Health Care. Soc. Sci. Med. 1998, 26, 877-878.

29. Suk, J.E.; Lopalco, P. Hesitancy, Trust and Individualism in Vaccination Decision-Making. Available online: https://www. researchgate.net/publication/291368600_Measuring_vaccine_confidence_Introducing_a_global_Vaccine_Confidence_Index (accessed on 20 February 2015).

30. Larson, H.J.; Schulz, W.S.; Tucker, J.D.; Smith, D.M. Measuring Vaccine Confidence: Introducing a Global Vaccine Confidence Index. PLoS Curr. 2015, 7. [CrossRef] [PubMed]

31. Ambe, J.P.; Omotara, B.A.; Baba, M.M. Perceptions, beliefs and practices of mothers in sub-urban and rural areas towards measles and measles vaccination in Northern Nigeria. Trop. Dr. 2001, 31, 89-90. [CrossRef] [PubMed]

32. Langwick, S.A. Bodies, Politics, and African Healing: The Matter of Maladies in Tanzania; Indiana University Press: Bloomington, IN, USA, 2011.

33. Mokgobi, M.G. Understanding traditional African healing. Afr. J. Phys. Health Educ. Recreat. Danc. 2014, 20, 24-34. 
34. Odusanya, O.O.; Alufohai, E.F.; Meurice, F.P.; Ahonkhai, V.I. The determinants of vaccination coverage in rural Nigeria. BMC Public Health 2008, 8, 1-8. [CrossRef] [PubMed]

35. Stilwell, S. The Imposition of Colonial Rule. Colonial Africa. Available online: https://www.bartleby.com/essay/ The-Imposition-of-Colonialism-on-Africa-FKBRT6SQGDSX\#: \{\}:text=The $\% 20 \mathrm{imposition} \% 20 \mathrm{of} \% 20 \mathrm{colonialism} \% 20 \mathrm{on} \%$ 20Africa $\% 20$ drastically $\% 20$ reconstructed $\% 20$ the $\% 20$ continent, people $\% 2 \mathrm{C} \% 20$ culture $\% 2 \mathrm{C} \% 20$ and $\% 20$ resources. (accessed on 25 December 2021).

36. Bono, S.A.; Faria de Moura Villela, E.; Siau, C.S.; Chen, W.S.; Pengpid, S.; Hasan, M.T.; Sessou, P.; Ditekemena, J.D.; Amodan, B.O.; Hosseinipour, M.C.; et al. Factors affecting COVID-19 vaccine acceptance: An international survey among low- and middleincome countries. Vaccines 2021, 9, 515. [CrossRef]

37. Osuagwu, U.L.; Miner, C.A.; Bhattarai, D.; Mashige, K.P.; Oloruntoba, R.; Abu, E.K.; Ekpenyong, B.; Chikasirimobi, T.G.; Goson, P.C.; Ovenseri-Ogbomo, G.O.; et al. Misinformation About COVID-19 in Sub-Saharan Africa: Evidence from a CrossSectional Survey. Health Secur. 2021, 19, 44-56. [CrossRef]

38. Sessa, F.; Salerno, M.; Esposito, M.; Di Nunno, N.; Zamboni, P.; Pomara, C. Autopsy Findings and Causality Relationship between Death and COVID-19 Vaccination: A Systematic Review. J. Clin. Med. 2021, 10, 5876. [CrossRef] [PubMed]

39. Abu, E.K.; Oloruntoba, R.; Osuagwu, U.L.; Bhattarai, D.; Miner, C.A.; Goson, P.C.; Langsi, R.; Nwaeze, O.; Chikasirimobi, T.G.; Ovenseri-Ogbomo, G.O.; et al. Risk perception of COVID-19 among sub-Sahara Africans: A web-based comparative survey of local and diaspora residents. BMC Public Health 2021, 21, 1-13. [CrossRef] [PubMed]

40. Sturm, L.A.; Mays, R.M.; Zimet, G.D. Parental beliefs and decision-making about child and adolescent immunization. J. Dev. Behav. Pediatrics 2005, 26, 441-452. [CrossRef] [PubMed]

41. Teitler-Regev, S. Factors Affecting Intention among Students to Be vaccinated against A/H1N1 Influenza: A Health Belief Model Approach. Adv. Prev. Med. 2011, 2011, 353207. [CrossRef] [PubMed]

42. Streefland, P.; Chowdhury, A.M.R.; Ramos-Jimenez, P. Patterns of vaccination acceptance. Soc. Sci. Med. 1999, 49, 1705-1716. [CrossRef]

43. Ndiaye, N.M.; Ndiaye, P.; Diédhiou, A.; Guèye, A.S.; Tal-Dia, A. Facteurs d'abandon de la vaccination des enfants âgés de 10 à 23 mois à Ndoulo au Sénégal en 2005. Cah. D'études Rech. Francoph./St. 2009, 19, 9-13.

44. Onsomu, E.O.; Abuya, B.A.; Okech, I.N.; Moore, D.; Collins-McNeil, J. Maternal Education and Immunization Status Among Children in Kenya. Matern. Child Health J. 2015, 19, 1724-1733. [CrossRef] [PubMed]

45. Abuya, B.A.; Onsomu, E.O.; Kimani, J.K.; Moore, D. Influence of Maternal Education on Child Immunization and Stunting in Kenya. Matern. Child Health J. 2011, 15, 1389-1399. [CrossRef] [PubMed]

46. Benninghoff, B.; Pereira, P.; Vetter, V. Role of healthcare practitioners in rotavirus disease awareness and vaccination-insights from a survey among caregivers. Hum. Vaccines Immunother. 2020, 16, 138-147. [CrossRef]

47. Kumar, S.; Preetha, G.S. Health Promotion: An Effective Tool for Global Health. Indian J. Community Med. Off. Publ. Indian Assoc. Prev. Soc. Med. 2012, 37, 5. [CrossRef] [PubMed] 